\title{
Meninos Públicos na Via Pública: O Malabarismo como Espetáculo ou a Reprodução da Pobreza
}

\section{Public boys in Public Roads: The Joggling act as a epectacle or the reproduction of proverty}

\author{
Marlene Almeida de Ataíde*
}

\begin{abstract}
Resumo: Este artigo resulta de uma pesquisa qualitativa que teve como abordagem a metodologia da história oral e como objetivo apresentar as faces do trabalho infantil na contemporaneidade. Não obstante, as proibições por parte de Organizações Governamentais e Não Governamentais por considerar as consequências nocivas que o trabalho precoce pode acarretar na vida de crianças e adolescentes, os resultados não têm sido suficientes para deter os índices de crianças e adolescentes que são flagradas nas mais diversas atividades, não obstante as proibições. $O$ trabalho infantil além de ferir os direitos consagrados de crianças e adolescentes conforme prescreve o Estatuto da Criança e do Adolescente, Lei $n^{\circ}$ 8069/90, se torna, cada vez mais, uma forma de aprofundamento e reprodução da pobreza e das desigualdades sociais.
\end{abstract}

Palavras-chave: Criança e adolescente. Trabalho infantil. Pesquisa qualitativa. História oral.

\begin{abstract}
Absctract: This article results from a qualitative research which was to approach the methodology of oral history, and aims to present the faces of child labor in the contemporary world. Notwithstanding the prohibitions on the part of governmental and non-governmental organizations by considering the harmful consequences that early work may result in lives of children and adolescents, the results have not been enough to stop the indexes of children and adolescent who are caught in various activities, despite the prohibitions. Child labor in addiction to injure the rights of children and adolescents prescribed in the Statute of the Child and Adolescent law No 8069/90, is increasingly becoming a way of deepening and reproduction of property and social inequalities.
\end{abstract}

Keywords: Child and adolescente. Child labor. Qualitative research. Oral history. Recebido em: 24/11/2015. Aceito em: 05/04/2016

'Doutora e Mestre em Serviço Social pela Pontifícia Universidade Católica - PUC/SP. Graduada em Serviço Social pela Faculdade Fransciscana de Bragança Paulista, FFBPSP/SP. Professora do Curso de Serviço Social da Faculdade Tijucussu - São Caetano do Sul SP e Universidade de Santo Amaro-UNISA. E-mail: maataide@yahoo.com.br. 


\section{Introdução}

A história da criança e do adolescente no Brasil é demarcada entre antes e depois do Estatuto da Criança e do Adolescente - ECA - Lei n. 8.069, de 13 de julho de 1990. O advento do ECA contrapõe-se historicamente a um passado de controle e de exclusão social, elevando todas as crianças e os adolescentes à categoria de cidadãos. Com isso, a ruptura com o paradigma da situação irregular - Código de Menores, Lei n. 6.697, de 10 de outubro de 1979 -, que deveria acontecer, sobretudo, nas práticas sociais, não somente no âmbito da lei, abriria caminhos para uma nova realidade histórico-social.

O próprio processo de elaboração da lei já estabeleceu algumas diferenças. O ECA foi elaborado pela sociedade, ouvindo inclusive as crianças e os adolescentes, por intermédio do Movimento Nacional de Meninos e Meninas de Ruas. O processo foi coordenado pelo Fórum do Departamento da Criança e do Adolescente (DCA), que na época era formado por representantes de órgãos governamentais e não-governamentais, cabendo aos juristas participarem apenas da redação.

Outro aspecto importante é que o antigo Código de Menores era destinado às crianças pobres, carentes e abandonadas e o novo diploma legal é destinado a todas indistintamente. A partir dele, a criança se torna sujeito de direitos e não mais objeto. Isto significa que ela adquire direitos de cidadania e pode, inclusive, acionar os órgãos competentes quando seus direitos forem violados. O Código de Menores tinha caráter jurídico e era centralizador, enquanto que o ECA tem caráter jurídico e social e estabelece a descentralização, a partir da criação do sistema de garantia de direitos, que prevê a criação de uma série de organismos como os conselhos paritários e tutelares, delegacias especializadas para cuidar de crimes que envolvam crianças e adolescentes, além de garantir direitos sociais, como saúde, educação, esporte e lazer.

Após a promulgação do ECA, foram elaborados e instituídos dois documentos da mais alta relevância, dada a especificidade do tema, que se referem às Regras Mínimas das Nações Unidas para a Prevenção da Delinquência Juvenil (Diretrizes de Riad) e às Regras Mínimas das Nações Unidas para a Proteção dos Jovens
Privados de Liberdade, ambos aprovados em novembro de 1990 preconizando um novo olhar sobre os jovens.

O ECA é considerado internacionalmente avançado em termos de direitos humanos, porque se coaduna com as premissas de organizações mundiais de proteção à infância e adolescência. Todavia, nota-se uma imensa lacuna entre a sua proposta e a realidade concreta de crianças e adolescentes brasileiros. Percebe-se que, na maioria das vezes, as proposições da lei não passam de meras formulações, apresentando um grande vazio entre estas formulações e suas operacionalizações.

Portanto, no contexto social e histórico da sociedade brasileira, o ECA veio para garantir a proteção integral à criança e ao adolescente. Transformou radicalmente o direcionamento do antigo Código de Menores - baseado na doutrina da situação irregular - e passou a considerar criança e adolescente como pessoas de direito e em condições peculiares de desenvolvimento. Dessa forma, o ECA rompe com paradigmas antiquados que não contemplavam uma política que efetivasse os direitos de crianças e adolescentes. Contudo, passados mais de 24 anos após a promulgação desse diploma legal ainda nos deparamos com a tendência colocada pela atual sociedade, ou melhor, para lembrar Guy Debord (1997) na sua obra intitulada " $A$ sociedade do espetáculo", essa sociedade tem ainda como lema caracterizar meninos e meninas pobres como aqueles que vivenciam formas frágeis e insuficientes de inclusão no contexto de uma nova desigualdade social: aquela que implica o esgotamento das possibilidades de mobilidade social para a maioria da população.

\section{Trabalho infantil: breves considerações}

A exploração do trabalho infantil se torna evidente no final do século XVIII e início do século $\mathrm{XIX}$, período esse marcado pelas transformações políticas e econômicas que iniciam na era industrial (HOBSBAWM, 2007). Primeiramente o processo inicia na Europa e se expande por toda a esfera terrestre.

[...] o capitalismo não inventou o trabalho infantil, mas criou as condições para que as crianças não só fossem transformadas em adultos precoces, em trabalhadores 'livres',

146 Emancipação, Ponta Grossa, 16(1): 145-161, 2016. Disponível em <http://www.revistas2.uepg.br/index.php/emancipacao> 
como destituídas de uma tradição em que trabalho e relações familiares, como eram vividas nas indústrias e domicílios, permitiam a sua reprodução enquanto criança. (THOMPSON, 1987, Apud MINAYO-GOMEZ; MEIRELLES, 1997, p. 136).

Thompson (2002) frisa que o trabalho infantil não é um dado recente, contudo ele adquire um novo sentido, face à exploração da mais-valia. Referido autor ressalta que a criança integrava a economia familiar e agrícola anterior aos anos de 1780, e inclusive, determinadas tarefas, como por exemplo limpar chaminés e trabalhar em navios, eram atribuídas às crianças pobres e órfãs antes da revolução industrial. Essas tarefas eram consideradas piores do que muitas atividades na fábrica. Contudo, esses fatos isolados não eram destinados à exploração de mais valor e nem predominantes: "[...] a forma predominante de trabalho infantil era a doméstica ou a praticada no seio da economia familiar. As crianças que mal sabiam andar podiam ser incumbidas de apanhar e carregar coisas" (THOMPSON, 2002, p. 203).

São relatados pelo autor depoimentos de crianças carregando algodão na peneira, estendendo o algodão solto, girando manivelas, limpando o domicílio, preparando pão e cerveja como exemplos de trabalhos realizados antes da exploração de crianças para a produção de mais-valia. Muitas famílias tinham interesse nas atividades que complementavam rendimentos com a ajuda da criança. Mas, em comparação ao trabalho industrial, as atividades domésticas eram mais variadas e não havia prolongamento ininterrupto, mas um ciclo de tarefas. A introdução era gradual e respeitava as idades, ou seja,

Nenhuma criança tinha que pisar sobre o algodão oito horas por dia, seis dias por semana. Em síntese, podemos supor que havia uma introdução gradual ao trabalho que respeitava a capacidade e a idade da criança, intercalando-o com entrega de mensagens, a colheita de amoras, a coleta de lenha e as brincadeiras. Acima de tudo, o trabalho era desempenhado nos limites da economia familiar, sob cuidado dos pais (THOMPSON, 2002, p. 25).

Obrigados a essa cruel situação, crianças e jovens iam à ruína física e mental, enquanto que a necessária ocupação extradomiciliar das mães condenava as crianças ao descuido, ou seja, "[...] alimentação inadequada, falta de alimentação, administração de opiatos, etc., para acalmar bebês famintos e ao envenenamento proposital (MARX, 1988, p. 23).

Como exemplo das péssimas condições do trabalho domiciliar e da contradição existente na proibição de menores de treze anos trabalharem nas indústrias sem frequentarem a escola, Marx (1988) evidencia que na produção de carvão, nas olarias e na mineração, onde as máquinas, em 1866, ainda eram raras, o trabalho ia das cinco da manhã às oito da noite com emprego de crianças desde quatro anos de idade:

Crianças de ambos os sexos são empregadas a partir dos 6 e até mesmo dos 4 anos de idade. Trabalham o mesmo número de horas, frequentemente mais que os adultos. $O$ trabalho é duro e o calor do verão aumenta ainda mais o esgotamento. Numa olaria de Mosley, por exemplo, uma moça de 24 anos fazia diariamente 2 mil tijolos, ajudada por 2 garotas menores de idade como auxiliares, que traziam o barro e empilhavam os tijolos. Essas garotas carregavam diariamente 10 mil toneladas de barro por uma aclive escorregadio de uma escavação com uma profundidade de 30 pés, e numa distância de 210 pés (MARX, 1988, p. 71).

As ilustrações demonstram claramente que a exploração do trabalho infantil potencializa a mais-valia imediatamente, mas, em doses exageradas, ameaça a reprodução do sistema, elevando a degeneração e a mortalidade entre os trabalhadores precoces. Por isso, avançam as leis fabris que limitam a jornada de trabalho por idade e obrigam o ensino escolar para as crianças nas fábricas. Conforme o autor, nada poderia ser melhor para o modo capitalista de produção do que as leis que, por meio da coação do Estado, regulam formas de exploração com providências mínimas de saúde e higiene aos trabalhadores.

De acordo com Vianna (2004), o trabaIho infantil ficou visível na Revolução Industrial, ocorrida na Inglaterra no século XVIII, em que as crianças começavam a trabalhar por volta dos seis anos de idade, com funções extenuantes, sem repouso e recebendo cerca de um quarto do salário garantido a um adulto. No entanto, passados dois séculos da Revolução Industrial, a despeito das transformações ocorridas no mundo, e ainda a luta de organismos internacionais e 
nacionais contra a prática do trabalho precoce, muito se tem a percorrer nesta direção, especialmente em nosso país, signatário de uma ampla legislação de proteção à criança e ao adolescente e da proibição do trabalho infantil.

\section{O trabalho infantil e as normativas legais}

O trabalho infantil é um problema que afeta o mundo todo. Em torno de 170 milhões de crianças e adolescentes perdem a infância e a adolescência, porque precisam ou são obrigados a trabalhar

(Kailash Satyarthi - Prêmio Nobel da Paz)

Debater sobre a realidade do trabalho infantil na contemporaneidade significa trazer à tona o que se considera de mais intolerável que é a violação de direitos humanos e ainda negar os princípios fundamentais prescritos na ordem constitucional, ou seja, os princípios da proteção integral e da prioridade absoluta, que encontram fundamentos na normativa legal da dignidade humana, de modo a causar imediata e eficaz reação dos órgãos de proteção, especialmente aqueles incumbidos de assegurar e tutelar os direitos das crianças e adolescentes.

Nessa acepção do termo, o trabalho infantil se caracteriza por meio de atividades realizadas por crianças e adolescentes com idade inferior a 16 anos, que visem à obtenção de ganho para prover o sustento próprio e/ou da família, como também de quaisquer serviços que não tenham remuneração.

Embora o trabalho infantil tenha sido um fenômeno presente na história brasileira desde os tempos de colônia, o crescimento econômico e populacional vivenciado, sobretudo, a partir do século $X X$, levou a um aumento do número de crianças e adolescentes de até 18 anos trabalhando no país, notadamente entre aqueles afetados diretamente pela desigualdade na distribuição de renda (BRASIL, 2004).

Do ponto de vista da legislação, temos a Constituição Federal de 1988 que aponta a família juntamente com a sociedade e com o Estado como as primeiras instâncias sobre as quais recaem as responsabilidades da garantia dos direitos da criança e do adolescente. Em seu Artigo 227, esta Carta Magna traz a seguinte redação:
É dever da família, da sociedade e do Estado assegurar à criança e ao adolescente, com absoluta prioridade, o direito à vida, à saúde, à alimentação, à educação, ao lazer, à profissionalização, à cultura, à dignidade, ao respeito, à liberdade e à convivência familiar e comunitária, além de colocá-los a salvo de toda forma de negligência, discriminação, exploração, violência, crueldade e opressão.

O inciso XXXIII proíbe o "trabalho noturno, perigoso ou insalubre a menores de dezoito e de qualquer trabalho a menores de dezesseis anos, salvo na condição de aprendiz, a partir de quatorze anos" (CONSTITUIÇÃO FEDERAL, 1988). É importante frisar que há nessa temática uma forte relevância no que tange às contradições aparentes de direitos fundamentais, pois a Constituição Federal ao mesmo tempo em que veda qualquer trabalho anterior aos dezesseis anos, com exceção na condição de aprendiz, em seu art. $5^{\circ}$, inciso IX, permite a liberdade de expressão, artística, independentemente de censura e licença. No entanto, é comum observar a violação dos direitos humanos envolvendo crianças e adolescentes submetidos ao trabalho infantil artístico, especialmente no que diz respeito à aplicação da proteção integral e encontra-se amparada no ordenamento brasileiro em prejuízo da Convenção dos Direitos da Criança adotada em 1989 pela Organização das Nações Unidas - ONU. Nesse sentido, cabe algumas indagações que merecem reflexões: É verdade que do ponto de vista da teoria a proteção integral permite a garantia eficaz de direitos das crianças e adolescentes que são submetidas a atividades artísticas no Brasil? Os direitos humanos desses sujeitos estão sendo respeitados quando exibidos em programas de televisão ou propagandas e são submetidos às rotinas extenuantes para a gravação e decoração de textos? Como mudar a visão da sociedade e da família que aceita naturalmente o desenvolver desse trabalho precoce? Se a doutrina da proteção integral considera a criança e o adolescente como sujeitos de direitos, estes têm também garantido o direito à liberdade de expressão artística, mesmo que essa seja realizada em vias públicas, colocando a vida em risco para angariar ou não algum ou nenhum trocado? E em que parte se encontram os poderes constituídos que deveriam proteger essas crianças/adolescentes que permanecem 
fazendo espetáculos nas ruas públicas, sendo muitas vezes humilhados ou ignorados.

Ocorre a incidência dessa atividade principalmente em programas de televisão e na publicidade. Nessa seara, é regra o incentivo e interesse dos pais ou responsável legal na realização do trabalho da criança e do adolescente, seja pela projeção social que representa, seja pelas possibilidades econômicas que propicia. Por isso não tem sido rara a participação ou omissão dos pais em situações de trabalho artístico que caracterizam abuso e desrespeito (MEDEIROS NETO; MARQUES, 2013, p. 14).

No Estatuto da Criança e do Adolescente ECA, (Lei n 8.069/1990), há uma clara definição especificada em seus artigos 60 a 69, sobre a proteção integral à criança e ao adolescente no âmbito do trabalho.

Do ponto de vista da consolidação das Leis do Trabalho (CLT - Decreto 5.452/1943) - em seu Capitulo IV, Título III, dispõe sobre as possibilidades e condições de trabalho a pessoas com idade inferior a 18 anos.

Temos por outro lado o Decreto $n^{\circ}$ $6.481 / 2008$ o qual trata da proibição das piores formas de trabalho infantil, constando como proibidas 93 atividades para pessoas com idade inferior a 18 anos.

A Instrução Normativa $n^{\circ} 77 / 2009$, da Secretaria de Inspeção do Trabalho do Ministério do Trabalho e Emprego, dispõe sobre a atuação da inspeção do trabalho no combate ao trabalho infantil e na proteção do trabalhador adolescente. A Inspeção do Trabalho tem por função fiscalizar o cumprimento da legislação trabalhista, dentre outras atribuições.

Nessa luta para coibir ou erradicar o trabalho infantil, muitos países se uniram para defender os direitos da criança e do adolescente e combater esse tipo de trabalho prejudicial para aqueles que se encontram em fase de desenvolvimento. Dessa união nasceram diversos acordos internacionais, alguns especialmente importantes na defesa dos direitos da infância com relação ao trabalho. No dia 20 de novembro de 1959, a Assembleia Geral das Nações Unidas aprovou a "Declaração dos Direitos da Criança". Em 1989, a Assembleia das Nações Unidas adotou a "Convenção sobre os Direitos da Criança" a qual, entre outros assuntos, determinou a proteção da criança contra a exploração econômica bem como contra a realização de qualquer trabaIho que possa ser perigoso ou interferir em sua educação, ou que seja nocivo para sua saúde, para seu desenvolvimento físico, mental, espiritual, moral ou social. Afirmou, ainda, que os países devem definir uma idade mínima para admissão em empregos, bem como horários e condições. Essa Convenção foi ratificada pelo Brasil em 1990. De grande importância também é a Convenção 182 de 1999, da Organização Internacional do Trabalho (OIT) que foi ratificada em 2000 pelo Brasil e dispôs sobre a proibição das piores formas de trabalho infantil, apontando atividades cuja realização é proibida para crianças com menos de 18 anos de idade e determinando a urgência na sua eliminação. $E$ outra de igual relevância é a Convenção 138 de 1973 da OIT, que foi ratificada em 2002 pelo Brasil e define a imposição de uma idade mínima para o emprego ou trabalho levando em consideração, dentre outros fatores, a escolaridade obrigatória e a proteção à saúde e à segurança da criança. Essas convenções internacionais deram origem a várias normas de proteção à criança e ao adolescente nos diversos países que as ratificaram.

Finalmente, a Convenção 182, aprovada pela ONU em 1999 e ratificada em 2 de fevereiro de 2000 pelo Brasil, conforme mencionado anteriormente, versa sobre as piores formas de trabalho infantil e visa suplementar e priorizar esforços de prevenção e erradicação do trabalho infantil (BRASIL, 2004).

O Estatuto da Criança e do Adolescente vislumbra educação em seu sentido mais amplo, englobando o ensino regular e atividades educativas informais. A Constituição Federal define ainda a necessidade da educação para o trabalho. A lei menciona o termo ensino metódico, que deve ser ministrado em entidades apropriadas, como os SENAC (Serviço Nacional de Aprendizagem Comercial), SENAI (Serviço Nacional de Aprendizagem Industrial) e SENAR (Serviço Nacional de Aprendizagem Rural).

O Estatuto da Criança e do Adolescente em seu artigo 53 prevê os direitos da criança e do adolescente, da seguinte forma: "A criança e o adolescente têm direito à educação, visando ao pleno desenvolvimento de sua pessoa, preparo 
para o exercício da cidadania e qualificação para o trabalho, assegurando-lhes":

I- Igualdade de condições para o acesso e permanência na escola; II- Direito de ser respeitado por seus educadores;

III- Direito de contestar critérios avaliativos, podendo recorrer às instâncias escolares superiores;

IV- Direito de organização e participação em entidades estudantis;

V-Acesso à escola, pública e gratuita próxima de sua residência.

O Estatuto da Criança e do Adolescente em seu artigo 54 define os deveres do Estado em relação à criança e ao adolescente: É dever do Estado, assegurar à criança e ao adolescente:

I- Ensino fundamental, obrigatório e gratuito, inclusive para os que a ele não tiverem acesso na idade própria;

II- Progressiva extensão da obrigatoriedade e gratuidade do ensino médio;

III- Atendimento educacional especializado aos portadores de deficiência, preferencialmente na rede regular de ensino;

IV- Atendimento em creche e pré-escola às crianças de zero a seis anos de idade;

V- Acesso aos níveis mais elevados de ensino, de pesquisa e da criação artística, segundo a capacidade de cada um;

VI- Oferta de ensino noturno regular, adequado às condições do adolescente trabalhador;

VII- Atendimento no ensino fundamental, através de programas suplementares de material didático-escolar, transporte, alimentação e assistência à saúde.

Parágrafo $1^{\circ}-\mathrm{O}$ acesso ao ensino público e gratuito é direito público subjetivo;

Parágrafo $2^{\circ}$ - $O$ não-oferecimento do ensino obrigatório pelo Poder Público ou sua oferta irregular importa responsabilidade da autoridade competente.

Por outro lado, nos estudos e debates contemporâneos sobre o trabalho infantil parece haver consenso no que diz respeito aos diferentes fatores que recaem sobre essa problemática. Dentre os quais apontam as condições de pobreza das famílias e, por isso, a necessidade de complementação da renda familiar; o modelo do sistema econômico, que gera a desigualdade social; o mercado de trabalho, que aceita a inclusão de crianças e de adolescentes; a inserção precária dessas crianças e adolescentes no sistema educacional; o nível educacional dos pais 3 e os aspectos culturais que determinam a percepção sobre o trabalho.

No caso brasileiro, o trabalho infantil, ao longo da história, nunca foi representado como fenômeno negativo na mentalidade da sociedade brasileira. Até a década de 1980. O consenso em torno desse tema estava consolidado para entender o trabalho como sendo um fator positivo no caso de crianças que, dada sua situação econômica e social, viviam em condições de pobreza, de exclusão e de risco social. Tanto a elite quanto as classes mais pobres compartiIhavam plenamente dessa forma de conceber o trabalho infantil.

\section{A construção de um cenário}

"Tenho uma espécie de dever de sonhar sempre, pois, não sendo mais, nem querendo ser mais, que um espectador de mim mesmo, tenho que ter o melhor espetáculo que posso. Assim me construo a ouro e sedas, em salas supostas, palco falso, cenário antigo, sonho criado entre jogos de luzes brandas e músicas invisíveis" (Fernando Pessoa).

Diariamente, por motivo de força de trabalho, atravesso o cruzamento das Avenidas do Estado e Dom Pedro I, no bairro do Ipiranga- SP. Chamava-me a atenção que nos mesmos horários um grupo de três meninos cujas fisionomias ficaram e continuam marcadas, ou melhor, descrevendo-os: franzinos, descalços e com vestes simples, geralmente shorts ou bermudas, dois tacos de madeira nas mãos confeccionados com cabo de vassoura e boné na cabeça realizam um espetáculo a céu aberto, como se estivessem num picadeiro fazendo o papel de palhaços. Porém não provocam risos nos motoristas que trafegam por aquela via púbica. Pelo contrário, a primeira providência dos motoristas é erguer as portas dos seus carros com um olhar de repúdio e preconceito, talvez, pela desconfiança, nesses tempos em que a violência reina soberana nas pequenas, médias e grandes cidades. Estes meninos que não contam com mais de 14 anos de idade fazem evoluções na medida em que os 
carros se perfilam no semáforo. Avançam de forma destemida nas fileiras de carros. Em poucos segundos fazem uma breve reverência e iniciam seu número, mantendo o cabo de vassoura emborrachado fazendo girar jogando-o para cima e aparando-o novamente com bastante destreza. Sentindo-se vitoriosos neste cenário a céu aberto curvam-se solenemente para os carros, tiram o boné e começam a andar por entre as filas, recolhendo uma moeda aqui e outra, acolá. Ao observar esta cena cotidianamente no meu percurso comecei a indagar: Onde estão as políticas públicas que se destinam a estes meninos, em especial a educação enquanto ferramenta para transformá-los e reverter a situação pela qual estão experimentando/vivendo, faça sol ou chuva? Como os dias foram passando e estes meninos continuavam nos mesmos lugar e horário comecei a responder a minha indagação, ou seja, parece que a política de educação e as demais instâncias do poder público que deveriam protegê-los, nunca estiveram presentes para apreciar o espetáculo público desses meninos malabaristas naquele semáforo. Enquanto a educação e as demais políticas públicas sociais não aparecem neste cenário para assegurar a formação e o desenvolvimento físico, intelectual e moral desses meninos, o respeitável público, trafegando no conforto dos seus carros, assiste a tudo impassível, quase como se o espetáculo não lhes dissesse respeito.

Foi diante de tal cenário, e, indignada com a situação, num determinado dia passando naquela via sem a desenfreada pressa diária, abordei um dos meninos para uma conversa numa rua bem próxima ao semáforo. Esse menino concordou e foi ao meu encontro. Indaguei o seu nome, idade, se tinha família, se estudava o motivo de permanecer no semáforo, se não tinha medo de ser atropelado, porque não estava na escola e sim no semáforo. Feitas as indagações perguntei se podia num outro dia conversarmos mais demoradamente, colocando a minha posição de pesquisadora. Eis que me fez a seguinte pergunta: "Vou aparecer na TV tia". E desta forma marcamos os encontros, quando então me apresentou os outros dois meninos dispostos em colaborar. A única ressalva feita foi para que as entrevistas fossem feitas num local distante do trabalho (semáforo) para o patrão, ou seja, aquele os utiliza no trabalho infantil, ou como disseram o "o tio do farol", não saber nem mesmo "brigar com eles". Para preservar suas identidades foram atribuídos codinomes. Assim combinamos os nossos próximos encontros, ou seja, no dia 12/05/2014 às $14 \mathrm{~h} 30 \mathrm{~min}$ entrevistaria o Guilherme. No dia $19 / 05 / 2014$, às $13 \mathrm{~h} 00 \mathrm{~min}$ horas o Lucas e finalmente o Tiago no dia 16/06/14 às $15 \mathrm{~h} 00 \mathrm{~min}$.

\section{Apresentando os meninos públicos na via pública}

"Essa história começa ao rés do chão, com passos. São eles o número, mas um número que não constitui uma série. Não se pode contá-lo, porque cada uma de suas unidades é algo qualitativo: um estilo de apreensão táctil de apropriação cinética. Sua agitação é um inumerável de singularidades. Os jogos dos passos moldam espaços. Tecem os lugares"! (DE CERTEAU)

Os meninos que participaram deste estudo residiam no mesmo bairro, constituindo, dessa forma, laços de vizinhança. Foram escolhidos de forma intencional, por terem o perfil que se busca compreender sobre a infância e o trabaIho infantil. As questões do roteiro de entrevista referiam-se às atividades praticadas por eles, ou seja, o malabarismo na via pública, o contexto em que se desenrolam e as motivações que os levam a praticá-las.

Guilherme, 12 anos, pais separados, reside no bairro de São Mateus, estudou a $1^{a}$ série do ensino Fundamental, foi expulso da escola aos 10 anos.

Lucas, 13 anos, pais separados, reside no bairro de São Mateus, abandonou a escola no $2^{\circ}$ ano do Ensino Fundamental.

Tiago, 13 anos, não conheceu os pais, foi criado em abrigo, fugiu, vive de favor na residência dos colegas Guilherme e Lucas, em São Mateus, não soube informar até que série estudou.

Conforme mencionado anteriormente, nos dias e horários combinados esperei os meninos numa rua próxima, sem muitos ruídos para iniciar a gravação da primeira entrevista.

O primeiro interlocutor a comparecer foi o Lucas, menino esperto, comunicativo, risonho, compleição franzina, afetivo, e pronto para colaborar, mesmo com receio de sofrer represálias. 
Observei que se sentiu importante por alguém desconhecido Ihe permitir atenção, algo difícil nas suas experiências.

O segundo entrevistado foi Lucas. Apresentou-se um pouco tímido, mas afirmou que concederia a entrevista se tivesse como recompensa um pacote de biscoitos, pois não havia almoçado e estava com muita fome e sede. Diante da situação não tive como negar-lhe o pedido e levei-o a uma lanchonete próxima onde foi oferecido um saboroso lanche.

Por fim, a última entrevista foi com o Thiago. Menino de aparência sapeca, extrovertido e comunicativo. Antes do início da entrevista quis me apresentar um número de malabarismo e no final o aplaudi, momento em que deu um sorriso largo e agradeceu os aplausos.

Assim é que das atitudes de aproximação, respeito e empatia trazidas pelo pesquisador, virá a disponibilidade dos sujeitos e o seu envolvimento com a tarefa de informantes (o que amplia a possibilidade de validade dos dados obtidos), fazendo dela um momento de reflexão, retomada de fatos, valores e idéias do passado (quando este é o caso) e a gratificação com sua transmissão ao entrevistador (ALVES; SILVA, 1992, p. 64).

À parte o lado humano, esse tipo de coleta de dados coloca a necessidade de o pesquisador fazer o que Mettel (1988 apud Alves e Silva,1992) definem como sendo o "bom uso da tecnologia " e que significa nesse caso lançar mão do recurso "gravação" para poder ao mesmo tempo auferir a vantagem da maior preservação possível do discurso dos entrevistados, evitando seu comprometimento, bem como da própria interação, pela tarefa de tomar nota das respostas.

No que diz respeito ao recurso da técnica da gravação para a coleta de relatos orais, em particular quando se grava em fitas, tal recurso foi adquirindo relevância nas "[...] histórias de vida e depoimentos pessoais isto é pelas investigações ligadas à memória individual”. Na França essa técnica é chamada de 'arquivos orais', enquanto que em outros países recebe a denominação de 'informação viva' (QUEROZ, 1991, p. 73).

\section{Uma conversa sobre a história oral e a memória: ou, para início da conversa}

\begin{abstract}
"A recordação do passado é necessária para afirmar a própria identidade, tanto individual como de grupo. Um e outro também se definem, evidentemente, por sua vontade no presente e seus projetos de futuro; mas não podem prescindir dessa primeira lembrança" (Todorov).
\end{abstract}

"[...] as razões pra esse desejo de divulgar a própria experiência variam segundo cada pessoa e grupo [...] mas isso não é relevante para a questão aqui discutida" (Portelli, 1997)

Essa conversa com a história oral deve-se a uma formação acadêmica e/ou trajetória profissional como Assistente Social cujos caminhos percorridos foram se transformando em fatos que em muito contribuíram para buscar compreender sobre a história oral, pois, sem dúvida, tem suas raízes nessa trajetória na qual atuei majoritariamente com sujeitos sociais, especificamente, jovens institucionalizados para o cumprimento de medida socioeducativa de internação conforme prevê o Estatuto da Criança e do Adolescente - ECA.

Importante ressaltar que o Serviço Social enquanto uma profissão que atua eminentemente com sujeitos sociais, os profissionais, ao mesmo tempo em que são seres singulares, são também seres das relações em constante processo de desenvolvimento. Portanto, a atuação profissional e seu desenvolvimento são determinados pelas condições sócio-históricas, culturais e econômicas. Levando-se em conta a relação dialética, também este ser (Assistente Social) tem a sua parcela de contribuição a oferecer, quando determina essas condições na intervenção coletiva, ou seja, com outros homens. Desta forma, o ser social pensado no seu conjunto (sociedade) se constitui por essas relações que os homens mantêm entre si e com a natureza, as quais são mediadas principalmente pelo trabalho, pois a singularidade do ser social é a forma como as condições sociais, econômicas e culturais postas pela sociedade rebatem na sua individualidade e que se configura e legitima como uma prática interventiva e investigativa. Tem, por outro lado, na sua dimensão operativa a pesquisa como exercício fundamental de organização do saber 
sobre as diferentes expressões da questão social, com vistas à produção do conhecimento. O trabalho cotidiano demanda dados que invariavelmente não se encontram disponíveis nos registros ou cadastros dos campos ocupacionais. Dessa forma, a intervenção profissional requer, em muitas das vezes, que o profissional tenha conhecimento sobre processos em curso de determinados segmentos da sociedade que recorrem às instituições.

Portanto, o Assistente social é um profissional pesquisador, muitas vezes fazendo o papel de um "detetive". Na sua prática cotidiana, além de manipular documentos e arquivos, escuta as múltiplas vozes que circulam nos espaços sócio-ocupacionais, e, necessariamente é alguém envolvido com a oralidade enquanto metodologia de escuta na relação com o outro, pois busca complementar dados que são significativos, mas frequentemente, ausentes nos demais acervos. Porém, essa relação deve estar sempre embasada pela confiança mútua e pela ética que alicerça a profissão. Ou, "[...] Como somos agentes ativos da história e participantes do processo de fazê-la, cabe-nos, por outro lado, situar a ética profissional e a técnica no contexto de responsabilidades mais amplas, tanto individuais e civis como políticas" (PORTELLI, 1997, p. 13).

No aspecto de ser um profissional pesquisador e até certo ponto "detetive", vale-me Amorim, no seu belíssimo artigo denominado "O detetive e o pesquisador", ao enfatizar que,

Entre as atividades de detetive e de pesquisador, ambas de investigação e busca da verdade há alguns pontos em comum. [...] a cena aqui é a cena enunciativa, e que os dados não são trazidos por falas transparentes; ao contrário, a fala é problematizada, é instrumento de ação e ela própria está em jogo. [...] É que o detetive fica pouco tempo sozinho, em momentos de introspecção ou reflexão, e, ao mesmo tempo, poucas coisas acontecem sem que ele esteja presente. [...] pode-se quase dizer que o que ele descobre ele o faz a partir e por causa da sua presença nos acontecimentos. É que essa presença é, em grande parte, presença em interlocução. (AMORIM, 1999, p. 127-136-137).

Neste fazer profissional de escuta das múltiplas vozes que circulam cotidianamente, ouvem-se os relatos que compõem as memórias - as suas histórias no contexto das trajetórias de vida, ou seja, suas experiências, vivências e modos de vida, tanto do ponto de vista pessoal quanto social. Muitas das histórias relatadas e escutadas nos comovem por estar impregnadas pelas subjetividades de cada sujeito que narra tendo cada uma dessas narrativas, as suas particularidades e singularidades.

Recordar significa voltar ao tempo para trazer à tona as lembranças, vivências e as experiências imediatas das nossas vidas. Neste caso estamos falando da memória, que num primeiro momento expressa a presença do passado. Para o sociólogo francês Burke (2000), as memórias são construções dos grupos sociais. A memória, seja como história da sociedade ou não, tem o papel de nos libertar do passado.

Os estudiosos da História Oral Ferreira e Amado (2006); Pollack, (1989) assinalam que a memória é uma atualização do passado ou a presentificação do passado e é, também, o registro do presente que permanece como lembrança. $A$ memória pode ser considerada uma evocação do passado. É a capacidade que o homem possui de reter o tempo que se foi, salvando-o da perda total. A lembrança conserva aquilo que se foi e não retornará jamais. É nesta perspectiva que se pretende trazer à tona as narrativas dos sujeitos entrevistados, a partir das lembranças retidas na memória.

No que diz respeito à questão da subjetividade, Portelli (1997) não vislumbra a história oral enquanto um instrumento capaz de fornecer informações sobre o passado, ao ressaltar o seu interesse pela subjetividade daqueles que narram, ou seja, não o resgate da fala daqueles que estão numa condição de dominados ou de dominadores, ou o imediatismo para preencher as lacunas que lhes interessam, mas sim tem como alvo recuperar o vivido, de acordo com a concepção de quem o viveu.

Portelli (1997) vai além ao frisar que a subjetividade daquele que expõe fornecendo as fontes orais, é o elemento mais precioso que nenhuma outra fonte possui em medida igual. Assevera que a história oral mais do que falar sobre eventos, fala sobre significados, nela a aderência ao fato cede passagem à imaginação, ao simbolismo.

Dessa forma, a experiência acumulada durante uma trajetória profissional tem ainda, 
uma grande faceta na minha vida: ela sempre foi movida pela emoção, pela curiosidade, ou seja, a busca do novo, a necessidade de indagar sempre, não apenas pela mera curiosidade, mas principalmente enquanto pesquisadora atenta pelo que já está posto na sociedade, sobretudo a forma como tudo se organiza e como se pode repassar isso para as futuras gerações. Este pequeno espaço abreviado neste texto não tem a pretensão de recuperar uma intensa trajetória profissional, mas de afirmar que as primeiras aproximações sobre a metodologia da história oral devem-se à leitura da obra clássica de Ecléa Bosi, (1994) "Memória e sociedade: lembranças de velhos" por meio da qual reflito sobre o meu passado e passo a reformulá-lo de forma diferente, na busca de novas perspectivas, ou parafraseando Silva:

O desafio de um trabalho como este, com fontes orais, está na possibilidade de apreender as tensões entre grupos sociais e os sujeitos individuais nos contextos em que elas são produzidas. As fontes orais fornecem potencialmente elementos que permitem de uma forma muito mais orgânica apreender as dinâmicas dos grupos e dos sujeitos em seus afazeres, valores, normas, comportamentos, etc. Apreender tudo isso, significa trabalhar com a complexidade da realidade social (SILVA, 2000, p. 32).

Para Thompson (2002), a história oral possui natureza criativa e capacidade cooperativa entre os sujeitos, se destaca como uma ferramenta possível de ser utilizada em diversas atividades. Segundo o autor, o trabalho com fontes orais pode realizar-se em qualquer lugar, tendo em vista toda comunidade carregar em si uma história multifacetada de trabalho, vida familiar e relações sociais à espera de alguém que a traga para fora.

Nesta perspectiva, o alcance da utilização das fontes orais vai muito além da mera gravação de uma fita ou transcrição de uma entrevista escrita. Utilizar as técnicas de história oral possibilita aos sujeitos pesquisados desenvolverem habilidades linguísticas faladas na realização da entrevista em si.

\section{Pesquisa qualitativa: a guisa da fundamentação teórica}

O trabalho investigativo se pautou em uma pesquisa de natureza qualitativa - a qual indica uma relação dinâmica entre o sujeito e o mundo real, uma interdependência viva entre pesquisador e o sujeito da pesquisa - um vínculo indissociável entre o mundo objetivo e a subjetividade dos sujeitos no processo investigativo.

Preliminarmente, é importante compreender que a pesquisa qualitativa é um termo que não representa algo único ou monolítico, como pode parecer à primeira vista. De modo contrário, o conceito de pesquisa qualitativa requer que os seus pesquisadores lancem mão de outras áreas do saber para construir um estatuto teórico particular.

Assim, a pesquisa qualitativa pode ser compreendida como uma jornada, e como tal, trata-se de uma experiência relativamente longa, pois há um envolvimento direto com método, procedimentos, instrumentos, recursos e sujeitos do estudo, em cujo a presença do pesquisador em campo se torna um imperativo. Uma vez que os sujeitos, indivíduos ou organizações, decidem participar e se permitem ser entrevistados e fornecer informações, desencadeia-se uma colaboração. Uma das vantagens que a abordagem qualitativa apresenta é justamente a plasticidade que lhe é inerente. Enquanto, os métodos e técnicas quantitativos transmitem uma impressão de engessamento, as metodologias qualitativas oferecem ao pesquisador uma sensação de liberdade que, por sua vez, traz como risco a possibilidade de displicência metodológica no decorrer da investigação. Tal liberdade é geralmente interpretada pelos críticos como falta de rigor científico.

Howard Becker (1999) defende tal liberdade ao extremo, optando por um modelo artesanal de ciência. Para ele, todo pesquisador, a exemplo dos clássicos, Marx, Durkheim e Weber, deve ser também um metodólogo. Afirma que, "os sociólogos deveriam se sentir livre para inventar os métodos capazes de resolver os problemas das pesquisas que estão fazendo" (BECKER, 1999, p. 12). A pesquisa com abordagem qualitativa se distingue também pela maneira de aproximar sujeito e objeto, partindo do princípio de que ambos pertencem à mesma natureza (MINAYO; SANCHES 1993). 
De acordo com Minayo (2007), ao complementarmos o aspecto qualitativo do objeto estamos considerando como sujeito de estudo: gente, em determinada condição social, pertencente a determinado grupo social ou classe com suas crenças, valores e significados, sendo que esse objeto encontra-se em constante transformação.

Esse objeto que é sujeito se recusa peremptoriamente a se revelar apenas nos números ou a se igualar com sua própria aparência. Desta forma coloca ao estudioso o dilema de contentar-se com a problematização do produto humano objetivado ou de ir em busca também dos significados da ação humana que constrói a história. (MINAYO 2007).

Minayo (2007) frisa que o objeto é histórico, possui uma consciência histórica e mantém uma identidade com o sujeito das investigações. Afirma que o objeto é algo complexo, contraditório, inacabado e em permanente transformação. Portanto a sua construção é feita por meio de retoques sucessivos condizentes com a proposta teórico-metodológica adotada.

No enunciado de Chizzotti (2005), o objeto na ótica qualitativa não é um dado inerte e neutro, está possuído de significados e relações que sujeitos concretos criam suas ações.

Nesse sentido, ao adotar a abordagem qualitativa o pesquisador supõe haver uma relação dinâmica entre o mundo real do sujeito, entre o sujeito e o objeto, entre o objeto e a subjetividade do sujeito.

A pesquisa qualitativa propicia que os participantes possam pensar a respeito daquilo que está sendo pesquisado, pois as suas percepções e representações, estão presentes e isso valoriza o que os sujeitos têm a dizer. Evidenciar a percepção dos sujeitos é permitir entrar em cena com o sujeito da pesquisa, proporcionando uma nova ambiência em que se privilegiam instrumentos que superam o questionário, mas aqueles que incidem apropriadamente na oralidade, como o roteiro.

Outro aspecto vital da pesquisa qualitativa localiza-se na conexão do sujeito à estrutura, interpretando suas vivências cotidianas.

Assim, colocam-se alguns pressupostos que fundamentam a utilização das metodologias qualitativas de pesquisa, a saber:
'O reconhecimento da singularidade do sujeito' - entendendo-se que o sujeito é singular podemos reconhecer o caráter de singularidade de cada pesquisa, que deve fundamentar-se no favorecimento das condições para a sua revelação, expressa na oralidade e na contextualidade de sua existência. [...] 'O reconhecimento da importância de se conhecer a experiência social do sujeito' - as pesquisas qualitativas valorizam conhecer como se processa a experiência social dos sujeitos, superando as reduções pelas percepções apenas circunstanciais, evidenciando o necessário conhecimento do modo de vida, concreto, apreendido como o real vivido pelos sujeitos, apreendidos pelas expressões sobre suas crenças, valores, sentimentos e ainda pela apropriação de suas próprias experiências vivenciadas cotidianamente (MARTINELLI, 1999, p. 22-23).

Assim, "O reconhecimento de que conhecer o modo de vida do sujeito pressupõe o conhecimento de sua experiência social", e isso significa "o viver histórico cotidiano do sujeito e a sua experiência social expressando a sua cultura". (THOMPSON apud MARTINELLI, 1999, p. 24),

Martinelli (1999, p. 23) reconhece ainda que "[...] É em direção a essa experiência social que as pesquisas qualitativas, que se valem da fonte oral, se encaminham, é na busca dos significados de vivências para os sujeitos que se concentram os esforços do pesquisador". Não se trata, portanto, de uma pesquisa com um grande número de sujeitos, pois é preciso aprofundar o conhecimento em relação àquele sujeito com o qual estamos dialogando.

É necessário ressaltar a dimensão política da pesquisa qualitativa, tornando o pesquisador e os sujeitos pesquisados, como sujeitos políticos que se exercitam de acordo com suas opções políticas, num mesmo processo investigativo; o que caracteriza esse tipo de pesquisa como intencional na busca dos objetivos previamente e explicitamente definidos, caracterizados pela busca intencional dos sujeitos.

Focada no trabalho a ser realizado inspirei-me na seguinte premissa: para iniciar o processo de pesquisa, parte-se do próprio campo, de onde se descortinarão os caminhos a serem percorridos. As direções escolhidas para a investigação são primordialmente traçadas durante o próprio 
"pesquisar". Escolhe-se um ponto de partida. Dá-se início à investigação.

\section{Os resultados da pesquisa e análises}

Estabeleceu-se para esta pesquisa as seguintes categorias apoiadas numa perspectiva teórica:

- As lembranças da infância;

- Significados do trabalho infantil;

- A escola em suas vidas;

- O contexto em que ocorre o trabalho;

- Os motivos que os levam a praticar o malabarismo.

\section{As lembranças da infância}

"Não há alma que possa viver sem saudades. Lembrar é viver e reviver. A certeza do hoje nasce da lembrança do ontem: um homem sem recordações seria uma pedra inerte" (Olavo Bilac)

Nas suas narrativas, os meninos trazem as suas lembranças da infância, suas experiências que marcaram e ainda marcam as suas vidas a partir do que Benjamin (1994) atribui a experiências que são contadas 'boca a boca', pela narrativa, como meio de troca de vivências e recriação delas, por intermédio das histórias pertencentes às narrativas anônimas ao enfatizar que "[...] o narrador retira da experiência que ele conta [...] e incorpora as coisas narradas às experiências de seus ouvintes". (BENJAMIN, 1994, p. 201). As narrativas que seguem indicam que as lembranças retidas na memória dos meninos vão se forjando conforme os acontecimentos vividos e nesta perspectiva vejamos com relação à fase da infância.

AH! Dona! Eu não sei o que é infância. Mas acho que infância é brincar, mas eu não tinha brinquedos porque minha mãe não tinha dinheiro para me dar. Porque meu pai batia na minha mãe, ele bebia ai a minha mãe largou dele. Eu só brincava com sucatas que encontrava na rua e no Natal ia umas pessoas no beco onde eu moro e dava umas coisas pra gente. (Lucas)
Infância... infância... o que é isso! Minha mãe fala que infância de filho de pobre é trabaiar pra ajudar em casa. Eu só tive um carrinho de prástico que um moço me deu uma vez de natal. Eu trabaio desde os 9 anos. Minha mãe mora sozinha porque meu pai foi embora, mas não lembro dele. A minha mãe fala que meu pai batia nela e nos meus irmão, que ele bebia e não gostava de trabaiar. (Guilherme)

Eu não conheci nem meu pai nem a minha mãe. Eu fui criado num abrigo, mas eu fugi porque lá era muita bagunça e os moleques e os funcionários só queriam zuar comigo. Eu ganhava uns brinquedo de prástico no abrigo, mas depois os outros moleques roubava de $\mathrm{mim}$. Eu vivia saindo do abrigo e ficava na rua e depois eu voltava quando os guardinhas da Prefeitura me mandava pro... pro... Conselho Tutelar ai eles falavam um monte e me levava de volta pro abrigo. Depois eu fugi e não voltei mais. Eu queria conhecer a minha mãe, mas ninguém sabe onde ela tá. Agora depois que eu conheci meus amigos eles me levaram para a casa deles lá em São Mateus. (Tiago)

Cada menino vivenciou de seu modo uma infância pautada pela violência no ambiente familiar, como é o caso de Lucas e Guilherme, cujos genitores além de agredir suas mães possuíam hábitos etílicos. Estes meninos desde tenra idade vivem em condição de vulnerabilidades social e emocional, oriundos de famílias que pertencem à classe social pobre e sem referência paterna. Tiago sequer conheceu um dos pais, e passou a sua infância morando em abrigos. Atualmente mora de favor na casa dos amigos que o iniciaram na prática do malabarismo. Por outro lado, os dois amigos nem mesmo reúnem condições favoráveis para mantê-lo. Esses meninos trazem nas memórias apenas lembranças de uma infância perdida, permeada por vínculos instáveis, sem acesso aos recursos lúdicos básicos para crianças, o pouco que obtiveram foi por intermédio da caridade alheia.

\section{Significados do trabalho infantil}

Quando abordados sobre o significado do trabalho infantil nas suas vidas, relataram que:

Eu não sei o que é isso não! Eu só sei falar que eu trabaio desde os 6 anos, primeiro eu ia vender balas para minha mãe, eu ia nos farol lá na Celso Garcia, sabe onde fica dona? 
Depois eu aprendi com uns muleques lá do beco onde eu moro a fazer malabarismo com o cabo de uma vassouras que a gente cortava e ai eu fui para rua mesmo todo dia para ganhar um dinheiro pra minha mãe. (Lucas)

Uma muíe passou um dia aqui no farol e falou que nós tava fazendo trabaio infantil que é proibido e xingou nós e falou que ia chamar o Conselho Tutelar para levar nós, ai nós corremos e se escondemos, mas o Conselho não veio e ai nós voltamos para o farol. Eu trabaio aqui no farol dona para ajudar a minha mãe e comprar algumas coisas pra mim. Antes de vir pro farol ia pra feira e carregava as sacolas das senhoras até a casa delas e ganhava uns troco. Depois é que vim pro farol. (Guilherme)

Trabaio infantil é fazer o que nos faz agora né senhora? A primeira vez que comecei a trabaiar foi aqui no farol, porque antes eu não trabaiava, só ajudava as tias do abrigo a lavar as roupas, passar pano no chão, limpar nosso quarto, lavar a louças, essas coisas assim. Depois que eu sai do abrigo é que vim pro farol e to achando legal. É um dinheirinho pouco que a gente ganha mais dá pra comprar algumas coisas e ajudar a mãe dos amigos de fé que moro lá com eles. (Tiago)

Observa-se que apenas o menino Tiago acrescenta ter uma noção do significado do trabaIho infantil. Enquanto que para Lucas e Guilherme o significado dado é o de ajudar suas mães, pois o trabalho em suas vidas ocorreu em tenra idade, ou seja, aos 6 e 9 anos respectivamente. Há uma complexa situação que acomete crianças e adolescentes exercendo atividades nas ruas, $\mathrm{e}$ isso se torna agravante. A cada momento em que aumenta o grau de vulnerabilidade que se instaura na vida das famílias com menor acesso aos recursos públicos levando-as para modos de vida cada vez mais perversos, eleva ainda mais o índice de crianças e adolescentes envolvidos com o trabalho infantil. Dessa forma, as decisões das famílias decorrem principalmente do efeito combinado entre pobreza e mercado de trabalho. Ou, nos dizeres de Martins (2006, p. 14):

Milhões das nossas crianças, antes de aprenderem a rezar o pão nosso de cada dia, já saberão como é que em cada dia se ganha o nosso pão. Um quinto dos brasileiros trabalha antes do corpo se tornar adulto, antes que uma pessoa tenha condições de dominar fisicamente o instrumento de seu trabalho, de modo que milhões vão conhecer indefesos o trabalho como a crua forma em que a coisa domina a pessoa.

O trabalho infantil é uma categoria que se vincula às expressões da questão social, gerando a pobreza e atingindo principalmente sujeitos que se encontram em situação de maior vulnerabilidade social. Porém há discussões de que quanto mais pobre é a família, maiores são as possibilidades de se valerem dos trabalhos dos seus filhos, pois são essas crianças e adolescentes oriundos da classe social pauperizada que se iniciam no trabalho precocemente e, em sua maioria, utilizam os parcos ganhos para manter a subsistência da família.

Mais uma vez Martins vai nos alertar que:

Um país que faz da criança um adulto precoce, mas que insiste em tratar a criança como se criança fosse imatura, incapaz, dependente. Pode trabalhar, até manter a família, mas não pode interpretar o seu lugar no mundo, as vicissitudes que a vitimam, expressar sua visão de mundo, ser ouvida, fazer dos adultos a crítica social que os adultos fazem das crianças e dos adolescentes. (MARTINS, 2006, p. 14).

\section{A escola em suas vidas}

"A educação para o sofrimento evitaria senti-lo com relação a casos que não o merecem" (Carlos Drummond de Andrade)

Os meninos como venho denominando-os desde o início deste paper tiveram pouco acesso à escola, quando nas suas narrativas trazem as seguintes questões:

Sabe dona: meu negócio na escola era brincar, brincar de escorregar pelos corrimão, eu não gostava de estudar não! Eu só gosto de trabaiar para ajudar a minha mãe que ela não tem uma saúde muito boa sabe, ela toma uns remédios e fica dormindo, dormindo. Eu só estudei até a $1^{\text {a }}$ série, mas eu fui expulso da escola, porque eu peguei um moleque e bati nele porque ele me chamava de maloqueiro e eu não gostava. Ai um dia eu não aguentei e dei o maior pau nele e a professora falou que eu não ia mais estudar e ai a diretora fez um papel e falou que eu tava fora da escola, ai eu 
não quis mais estudar e ai eu vim pro farol pra ganhar uns trocado. (Guilherme)

Eu nunca gostei de estudar. Fui somente até a $2^{\mathrm{a}}$ série e abandonei a escola. Meu negócio era brincar de pipa e trabaiar para comprar minhas coisas, umas bolachas recheadas, uns doces da hora e levar algum pra minha mãe que não tá trabaiando. (Lucas)

Eu estudei um pouco, mas não sei ler direito, mas eu sei fazer o meu nome. Num tá bom dona! Mas lá no abrigo eles não falavam nada se a gente não estudava. Os moleques gostavam mesmo era de zuar, brincar, dormir tarde, ver filme na TV, essas coisas. Se eu for contar nos dedos eu fui pouquinho na escola. Acho que umas dez vezes (risos). (Tiago)

No decorrer do processo educativo de crianças e adolescentes é de fundamental importância a relação de parceria entre a família e a escola, para o bom desenvolvimento pessoal e social dos sujeitos. Não se pode conceber a formação de adultos que reúna condições para exercer a cidadania sem a existência desse grupo, pois tem a responsabilidade pela formação da personalidade do indivíduo.

Por outro lado, temos o Estatuto da Criança e do Adolescente, em vigor no nosso país desde julho de 1990, o qual, ao tratar dos direitos fundamentais das crianças e dos adolescentes, dedica a eles o direito à educação, fundamentados nos artigos 53 a 59. Esta lei, na sua elaboração, contou com a participação da sociedade civil, por intermédio de movimentos populares e entidades organizadas, incluindo técnicos da área da educação.

A UNICEF (Fundo das Nações Unidas para a Infância), organismo da ONU (Organização das Nações Unidas) acredita que, se os governos cumprissem seus compromissos legais com relação à educação, a ocorrência da exploração da mão-de-obra infantil seria significativamente limitada, pois essas crianças são comprovadamente exploradas em razão também das condições sociais enfrentadas pelo Brasil, sem perspectiva de melhoras. A exploração do trabalho dessas crianças apresenta-se, no contexto nacional, como decorrência da miséria do povo e do descaso da sociedade, constituindo-se ponto de vergonha para um país que se diz em desenvolvimento e se quer democrático (SOUZA, s/d, s/p.).
Nas narrativas dos três meninos impressiona a forma como os seus direitos foram violados, pois os grupos como a escola e a família se mostraram ausentes no decorrer do processo educativo, como foi o caso de Guilherme e Lucas, enquanto que Tiago, o mais prejudicado de todos chegou a contar das vezes em que frequentou a escola ao alegar que: "Se eu for contar nos dedos eu fui pouquinho na escola. Acho que umas dez vezes". Ambos trazem nas suas narrativas o gosto pelas brincadeiras, próprias da fase que vivem, mas por outro lado não receberam estímulos, motivações, mesmo diante das dificuldades em dar continuidade aos estudos tendo optado pelo trabalho mesmo que na forma precária que se encontram.

[...] Milhões de crianças, no Brasil, não conhecem e nunca conhecerão a infância. Brincam de gente grande e não raro o fazem com alegria e paciência. São muitas as que brincam trabalhando, para cumprir indevida e injustamente a pena de Adão (MARTINS, 2006, p. 14).

\section{O contexto onde ocorre o trabalho}

O contexto em que o trabalho ocorre é descrito pelos meninos da seguinte forma:

Eu já tô aqui no farol faz uns dois anos. Eu vim porque o tio que mora perto da minha casa me chamou e falou que a gente podia ganhar um dinheiro e dividir com ele. Então assim, tem dia que dá pra tirar uns 10 real, uns 15 real, depende do dia, porque quando chove a gente não tira quase nada. Bom mesmo é no dia das crianças, dia de natal assim nesses dias as pessoas dão mais moedas. Mas sabe dona, tem algumas pessoas quando a gente chega perto fecha o vidro, acha que nós vai roubar elas. Mais nós não vai roubar ninguém... Nós só quer um trocado porque o que a gente faz o tio falou que é arte. Esse tio que trouxe nós pra cá tem mais dois farol, o outro é lá pros lado da radial leste. Todo dia ele passa aqui pra pegar as moedas e repartir com nós. (Guilherme)

Sabe como é um vai chamando o outro e eu vim porque o meu amigo me falou que tinha um trampo para ganhar dinheiro. Mais não é muito dinheiro não. No dia que chove fica difícil. Os carros passa tudo fechado e ninguém quer saber de nós. Mas já tô aqui faz um tem- 
po. $\mathrm{E}$ o dinheiro que a gente ganha tem que dar pro tio todo dia e depois ele reparte com a gente. É um dinheiro pouco, mas dá pra quebrar um galho, comprar algumas coisas pra ajudar em casa. (Lucas)

Os outros moleques que me deram esse trampo, já faz um tempo dona. Ai eu fui aprender fazer malabarismo rapidinho na casa do tio. Eu não tenho ninguém na vida e ainda vivo de favor na casa dos manos. O dinheiro que ganho depois que o tio divide com nós eu dou também aos manos pra ajudar na casa deles porque eu moro lá. (Tiago)

Nas narrativas acima enunciadas fica bastante claro que para o trabalho que executam não existe um processo seletivo, mas uma confiança que parte da figura do recrutador, ou seja, um adulto ensaia essa prática do malabarismo, e um vai chamando o outro, que também passa pelo mesmo processo de aprendizagem, para após ganhar a rua.

\section{Os motivos que os levam para a pratica do malabarismo}

A motivação para a prática do malabarismo é narrada pelos meninos de acordo com os excertos que seguem:

Eu comecei fazer malabarismo porque o tio falou que quem sabe fazer isso ganha um dinheiro e podia ajudar a minha mãe. Trabaiar na rua é puro divertimento. Antes eu vendia balas e chicletes. Ai ele falou que sabia fazer e levou nós pro quintal dele e ensinou como fazer. Mas eu queria mesmo era trabaiar num circo, porque eu gosto de circo, de palhaço. Mas enquanto não aparecer um circo a gente fica aqui mesmo no farol mostrando a nossa arte. A gente só não trabaia aqui sábado e domingo porque o movimento é mais fraco. $O$ movimento é melhor na hora do rango e quando as pessoas já tão indo embora pra casa, ai mais ou menos umas 7 horas da noite nós pega o nosso busão e ai vamos embora para casa para descansar. Eu gosto de ficar com os meus amigos aqui. (Guilhreme)

Antes eu vendia balinha na rua, e ai o tio falou que ia ensinar fazer malabarismo e levou a gente pro quintal dele e ensinou. Ele falou que a gente podia ganhar um bom dinheiro. Como nós precisa pra ajudar em casa, ai nos fomos lá e aprendemos ligeirinho. Mas também a gente se diverte muito aqui no farol, conhe- ce um bando de gente, mas tem aqueles que nem oia na gente. Fecha as portas do carro com medo pensando que nós vai roubar. Mas é melhor ta aqui com os meus amigos, do que ir vender maconha, porque teve um homem $e$ me chamou, mas eu não quis. To ligado nessas coisa de policia. (Lucas)

Eu só vim mesmo pra ganhar dinheiro e ficar com os meus amigos, porque os mano falou que a grana era boa. No começo eu pensei em vender balas, chicletes, doces, mas não tinha dinheiro para comprar as mercadoria. Ai aprendi rapidinho a fazer o malabarismo no quintal do tio. Mas se um dia eu tiver uma chance eu quero mesmo é ir pra o circo, eu quero mesmo é ser malabarista de circo. Aqui é bom, conhece muita gente, mas tem dia que a gente se cansa, não tem banheiro, é um problema, a gente come comida fria quando tem, ou então alguém dá alguma coisa e a gente só vai comer quando chega em casa de noite. Mas tem dia que o tio passa e dá uns baguio ai pra nós. A rua é boa, eu sempre gostei da rua, da liberdade da rua. (Tiago)

Na cena contemporânea o malabarismo vem se tornando uma oportunidade de "ganhar dinheiro", pois além de possibilitar parco retorno material, não há a necessidade de investir na compra de balas e chicletes para posterior revenda, conforme explicita a narrativa de Lucas de que "Antes eu vendia balinha na rua", ao passo que Tiago coloca a seguinte situação: "No começo eu pensei em vender balas, chicletes, doces, mas não tinha dinheiro para comprar as mercadorias".

Nas narrativas dos meninos há unanimidade de que a prática do malabarismo é uma forma de diversão, mas também de ganhar dinheiro para manter o sustento da família, a possibilidade de conhecer pessoas, criar novos vínculos, ficar com os amigos, brincar no local.

Não obstante, Martins (1993) ressalta que as crianças e os jovens quando submetidos ao trabalho infantil ou a exploração do trabalho vivenciam processos de coisificação e de embrutecimento da infância por meio das atividades pesadas, desgastantes e humilhantes.

Segundo Martins (1993), a concepção de criança sem infância diz respeito ao que está acontecendo com as crianças do Brasil e de outros países do chamado Terceiro Mundo. Nesse aspecto, o autor (1993, p, 16) afirma que "a criança absorvida, já como mão-de-obra excedente, 
pelo mercado de trabalho, tem seu destino inteiramente submetido ao processo de reprodução do capital e da sociedade." Nas considerações de Silva (2003, p. 54), a presença da criança no trabalho infantil compromete a infância, envolvendo "constrangimentos que desencadeiam o dilema e o impasse de ser duplamente alienado, ou seja, ser criança e ser adulto ao mesmo tempo, ser criança e trabalhar precocemente".

No que diz respeito à liberdade que a rua traz para Tiago, ou seja, "A rua é boa, eu sempre gostei da rua, da liberdade da rua”. Martins (1993, p. 14) alerta que "[...] É ilusória a liberdade gestada nessas condições porque é antes de tudo a liberdade da coisa, da mercadoria, da criança convertida em mão de obra real ou potencial”.

\section{Considerações finais}

Preliminarmente uma indagação se faz necessária a guisa das considerações finais deste trabalho, qual seja: O que nos desafia a repensar o que estamos fazendo de concreto para mudar o quadro de profundas desigualdades da sociedade brasileira? Se levarmos em consideração o texto do jornalista Arnaldo Jabor o qual trata da inquietude que deve tomar conta de todos nós cada vez que nos deparamos com meninos e meninas, cada vez mais novos, atuando como malabaristas nos sinais de trânsito das cidades. A presença do trabalho infanto-juvenil explorado nas ruas constitui uma realidade presente em diferentes capitais do nosso país e do mundo.

Essa configuração representa uma manifestação proveniente das expressões da questão social, que são históricas, econômicas e políticas no âmbito do espaço urbano, nas quais circunscrevem aspectos relacionados às desigualdades sociais e a pobreza para se compreender a realidade dos pequenos trabalhadores no contexto da cidade.

O contexto onde a pesquisa ocorreu exigiu da pesquisadora criação de estratégias de aproximação junto aos sujeitos. Nesse aspecto, foi acompanhando o cotidiano deles no semáforo por meio de caminhos que foram sendo trilhados de acordo com a realidade estudada.

Os significados conferidos à prática do malabares nos semáforos mostraram que a aproximação/associação dessa atividade com o circo, não raro, tomado enquanto espetáculo pelos diferentes sujeitos que compõem o contexto pesquisado, provoca reflexões que ocultam a exploração do trabalho infantil. A "imagem" ou "mensagem" que o malabarista transmite por meio de um show/espetáculo foi entendido aqui como uma das estratégias de trabalho desenvolvidas pelos sujeitos. Além do espetáculo que apresentam na performance do trabalho infantil nos sinais, desenvolviam outras habilidades, quais sejam, a adoção de uma postura mais polida e educada diante dos motoristas e transeuntes. Essas ações foram interpretadas como estratégias que desenvolvem, no intuito de cativar os motoristas, como tentativa de desconstruir uma "imagem" contrária ao imaginário social produzido na nossa história sócio-cultural e econômica que, não raro, associa a presença de meninos/ as na rua à desagregação social, à violência e à criminalidade. Em relação ao tema em questão se considera que ainda temos incipientes estudos referentes às experiências de infância no contexto da rua, no intuito de contribuir para a formulação de políticas públicas mais consistentes para a infância e a juventude.

\section{Referências}

ALVES, Zélia Mana Mendes Biasoli; SILVA, Maria Helena G. F. Dias da. Análise qualitativa de dados de entrevista: uma proposta. In: Paidéia, FFCLRP USP, Rib. Preto, 2, fev/jul, 1992.

AMORIM, Marília. O detetive e o pesquisador. Série Documenta nº 8, ano VI. Rio de Janeiro, 1999.

BECKER, Howard S. Métodos de pesquisa em ciências sociais. São Paulo: Hucitec, 1999.

BENJAMIN, Walter. O narrador: considerações sobre a obra de Nikoli Lestov. In: Magia e técnica, arte e política: ensaios sobre literatura e história da cultura. São Paulo: Brasiliense, 1994.

BOSI, Ecléa. Memória e sociedade: lembranças de velhos. São Paulo: Companhia das Letras, 1994.

BRASIL. UNICEF. Diretrizes das Nações Unidas para a Infância e a Adolescência - Diretrizes de Riad. Princípio n. 1. (Tradução Betsáida Dias Capilé). Brasília, Distrito Federal: Ministério da Justiça; Ministério de Ação Social - Centro Brasileiro para a Infância e a Adolescência; UNICEF, s/d. Disponível em: <http://www.mj.gov.br/sedh/dca/convriad.htm>. Acesso em: 05 jun. 2014. 
. Regras mínimas das Nações Unidas para a proteção dos jovens privados de liberdade. Princípio n. 2. (Tradução Betsáida Dias Capilé). Brasília, Distrito Federal: Ministério da Justiça; Ministério de Ação Social - Centro Brasileiro para a Infância e a Adolescência; UNICEF, s/d. Disponível em: <http:// www.mj.gov.br/sedh/dca/convriad.htm>. Acesso em: 05 jun. 2014.

Secretaria de Inspeção do Trabalho. Plano Nacional de Prevenção e Erradicação do Trabalho Infantil e Proteção ao Trabalhador Adolescente. Brasília: MTE, 2004. 82 p.

BURKE, Peter. História como memória social. In: Variedades de história cultural. Rio de Janeiro: Editora Civilização Brasileira. 2000.

CHIZZOTTI, Antonio. Pesquisa em ciências humanas e sociais. São Paulo: Cortez, 2005.

DEBORD, Guy. A sociedade do espetáculo: Tradução Estela dos Santos Abreu. Rio de Janeiro, Contraponto, 1997.

FERREIRA, Marieta de Moraes; AMADO, Janaína. (Orgs.). Usos \& abusos da história oral. Rio de Janeiro: FGV, 2006.

HOBSBAWN, Eric J. A Era das revoluções. São Paulo: Paz e Terra, 2007.

MARTINELLI, Maria Lúcia. (ORG.), Pesquisa qualitativa - um instigante desafio. Núcleos de Pesquisa 1. São Paulo: Veras, 1999.

MARTINS, José de Souza. O massacre dos inocentes: a criança sem infância no Brasil. (Coord.) São Paulo: Editora Hucitec, 1993.

. A infância breve na sociedade indiferente. In:

O Estado de São Paulo, 3 dezembro 2006. Caderno Aliás, p. 14.

MARX, Karl. O Capital (crítica da economia política). Livro 1. Vol II. São Paulo: Nova Cultural, 1988.

MEDEIROS NETO, Xisto Tiago; MARQUES, Rafael Dias. Manual de Atuação do Ministério Público na Prevenção e Erradicação do Trabalho Infantil/ Conselho Nacional do Ministério Público. Brasília: CNMP, 2013.

MINAYO-GOMEZ, Carlos; MEIRELLES, Zilah Vieira. Crianças e adolescentes trabalhadores: um compromisso para a saúde coletiva. In: Cad. Saúde Pública. Rio de Janeiro, 13(Supl. 2):135-140, 1997.
MINAYO, Maria Cecília de Souza. SANCHES, Odécio. Quantitativo-qualitativo: oposição ou complementaridade? Cad. Saúde Pública. Rio de Janeiro, 9 (3): 239-262, jul/set, 1993.

Ciência, técnica e arte: o desafio da ciência social. In: MINAYO, Maria Cecília de Souza. Pesquisa social: teoria método e criatividade. Petrópolis: Vozes, 2007 (Coleção Temas Sociais).

POLLACK, M.; Memória, Esquecimento, Silêncio; In: Estudos Históricos, Rio de Janeiro, vol.2, n. 3, 1989, p.3-15.

PORTELLI, Alessandro. Tentando aprender um pouquinho: algumas reflexões sobre a ética na História Oral. Projeto História 15. São Paulo, 1997.

QUEIROZ, Maria Isaura Pereira de. Variações sobre a técnica de gravador no registro da informação viva. São Paulo: T. A. Queiroz, 1991. - (Biblioteca básica de ciências sociais. Série 2. Textos; v. 7).

SILVA, Acildo Leite da. Memória, tradição oral e a afirmação da identidade negra: In: Movimento Revista da Faculdade de Educação da Universidade Federal Fluminense. $\mathrm{N}^{\circ} 1$, maio de 2000, Niterói-RJ: EDUFF, 2000. semestral.

SILVA, Maurício Roberto da. Trama doce- amarga: exploração do trabalho infantil e cultura lúdica. São Paulo: HUCITEC, 2003.

SOUZA, Giovana Paula de. A exploração do trabalho infantil e a fiscalização no município de Curitiba. Disponível em: http://mp.pr.gov.br/cpca/telas/ca_12_ junho_3_4.php Acesso em 30/dez./2014.

THOMPSON, Edward P. A formação da classe operária inglesa II (A maldição de Adão). São Paulo: Paz e Terra, 2002.

THOMPSON, Paul. A voz do passado: história oral. Trad. Lólio Lourenço de Oliveira. Rio de Janeiro - RJ: Paz e Terra, 2002.

VIANNA, Guarani de Campos. Direito infanto juvenil: teoria, prática e aspectos multidisciplinares. Rio de Janeiro: Freitas Bastos, 2004. 